\title{
Comunicação Organizacional, a sintese. Relações Públicas, a gestão estratégica
}

\author{
Organizational Communication, the synthesis. \\ Public Relations, the strategic management
}

Comunicación Organizacional, la sintesis.
Relaciones Públicas, la administración estratágica

Maria Helena Weber

- Doutora em Comunicação e Cultura pela Universidade Federal do Rio de Janeiro (UFRJ)

- Mestre em Sociologia pela Universidade Federal do Rio Grande do Sul (UFRGS)

- Bacharel em Relações Públicas e Propaganda pela UFRGS

- Professora do Curso de Comunicação Social da UFRGS

- Coordenadora do Programa de Pós-Graduação em Comunicação e Informação da UFRGS

- Produção científica e atuação vinculada ao campo da Comunicação Política

- Autora do livro Comunicação e espetáculos da política

- Organizadora das obras: Estudos de comunicação; Estratégias e culturas da comunicação; Tensões e objetos da pesquisa em comunicação

- Autora de diversos capítulos de livros e artigos em periódicos, como: "Comunicação: estratégia vital para a saúde" (1995); "Imagem pública" (2004); "Visibilidade e credibilidade: tensões da comunicação política" (2003); "Na comunicação pública, a captura do voto" (2007)

- maria.weber@ufrgs.br 
Este texto integra o debate sobre Comunicação Organizacional e Relações Públicas a partir de argumentos que defendem a complementaridade das duas denominações, analisadas sob perspectivas teóricas e pragmáticas. Assim Comunicação Organizacional é o resultado de todas ações institucionais, promocionais e mercadológicas utilizadas pelas organizações para gerar comunicação, apoio, visibilidade e imagem pública. Na mesma linha, Relações Públicas é a principal profissão com habilidades e competência para administrar estrategicamente essas ações para a construção integrada da imagem pública das organizações.

PALAVRAS-CHAVE: COMUNICAÇÃO ORGANIZACIONAL • RELAÇÕES PÚBLICAS • GESTÃO ESTRATÉGICA • IMAGEM PÚBLICA

\section{Abstract}

This text contributes to a debate on the concepts of Organizational Communication and Public Relations, with arguments that defend the complementarity of the two fields, analyzed from both theoretical and pragmatic perspectives. Thus, Organizational Communication is the result of all of the institutional, promotional and marketing-related actions used by organizations to generate communication, support, visibility and public image. Along the same lines, Public Relations is the main profession that has the skills and competencies to manage all such actions strategically, for integrated construction of the public image of the organizations.

KEYWORDS: ORGANIZATIONAL COMMUNICATION • PUBLIC RELATIONS • STRATEGIC MANAGEMENT • PUBLIC IMAGE

Resumen

Se busca contribuir al debate acerca de la Comunicación Organizacional y las Relaciones Públicas con argumentos que defienden la complementaridad de las dos denominaciones, analizadas desde perspectivas teóricas y pragmáticas. Así, la Comunicación Organizacional es el resultado de todas las acciones institucionales, promocionales y mercadotécnicas que las organizaciones utilizan para para obtener apoyo y generar comunicación, visibilidad e imagen pública. En esa misma línea, las Relaciones Publicas constituyen la principal profesión que tiene la habilidad y la competencia para integrar y administrar estratégicamente esas acciones y así construir de modo integrado la imagen pública de las organizaciones.

PALABRAS CLAVE: COMUNICACIÓN ORGANIZACIONAL • RELACIONES PÚBLICAS • GESTIÓN ESTRATÉGICA • IMAGEN PÚBLICA 
A s organizações públicas e privadas contemporâneas são compelidas a obedecer a regras impostas pela competição mercadológica, como a necessidade de obter uma imagem pública positiva e resultados com a comunicação adequada com seu público interno e investidores. Esse movimento, ininterrupto, depende da ativação de ações estratégicas e processos de comunicação das organizações que abrangem a disputa em torno da fidelidade, compreensão, votos e apoio mínimo de consumidores, audiência, cidadãos, eleitores, clientes. Para tanto, as organizações investem em estruturas, mídias, eventos e produtos informativos, promocionais e publicitários, capazes de ampliar o circuito de sua visibilidade em busca da formação de uma imagem e de opiniões rentáveis. Além disso, é necessário que suas metas sociais, políticas, econômicas e individuais repercutam, tanto do ponto de vista mercadológico quanto institucional. E isso requer profissionais capazes de operar a comunicação na contemporaneidade. Trata-se de um processo complexo e vulnerável, que exige planejamento, gestão e avaliação permanentes do que pode ser definido como a comunicação das organizações. A natureza dessa comunicação é política e estratégica, pois sua qualidade depende da integração de ações e da expertise de especialistas e profissionais oriundos do campo da Comunicação, especialmente de Relações Públicas, Publicidade e Jornalismo, além do Marketing e da Gestão de Pessoal, em departamentos, consultorias, agências e empresas.

A Comunicação Organizacional, portanto, é um conceito que abrange todos os meios, todas as ações e todas as profissões utilizadas por uma organização pública ou privada que deseja, principalmente, se fazer ver, gerar opiniões, receber investimentos, ocupar espaço no mercado e se relacionar de modo conveniente com seus públicos de interesse. Nesse sentido, Relações Públicas representam a profissão capaz de transformar essa comunicação em estratégica, de gerenciá-la de forma integrada. O investimento realizado por uma organização para informar e se comunicar com públicos e mercado, se responder a uma perspectiva integrada de planejamento, possibilitará que as informações acumuladas possuam unidade conceitual e visual, capazes, então, de gerar uma imagem positiva de repercussão mais permanente.

Por outro lado, é possível investir em um tipo de planejamento que privilegie um dos aspectos da Comunicação, tal como relações com a imprensa (Assessoria de Imprensa) ou relações com o mercado (campanhas publicitárias). A organização promove parte da sua totalidade e conseguirá com que a percepção ocorra de modo parcial e fragmentado mesmo com impacto e qualidade. Significa dizer que a criação ou a consolidação da identidade de uma organização e a consequente formação de uma imagem pública persistente somente será possível com a gestão estratégica de Relações Públicas capaz de integrar diferentes ações a diferentes públicos e interesses e, assim, formar a complexa rede de comunicação das organizações. A Comunicação Organizacional, portanto, é a soma dos modos com que a organização se comunica e cabe às Relações Públicas uma função política (SIMÕES,1995), que é a gestão desse processo. 
Podem-se compreender os conceitos Comunicação Organizacional e Relações Públicas como sendo complementares, pois pertencem à mesma natureza teórica. No entanto, o grau de desenvolvimento e institucionalização das profissões do campo da Comunicação, assim como o impacto gerado por suas ações, têm criado tensões teóricas, políticas, acadêmicas e profissionais importantes para o campo da Comunicação e provocado esse debate que pode ser norteado pela defesa de nichos de mercado ou pela compreensão da sua complementaridade. A partir dessa premissa, construí este texto.

\section{Limites conceituais e pragmáticos}

Entendo que as tensões de ordem prática são suficientes para defender as diferenças entre Comunicação Organizacional e Relações Públicas, assim como para mostrar sua complementaridade, como áreas homólogas, sem entender que sejam equivalentes. É preciso considerar a consolidação acadêmica, legal e profissional de Relações Públicas e a interação complexa entre as muitas modalidades de comunicação exercitadas pelas organizações públicas e privadas, as quais poderemos chamar de Comunicação Organizacional. O debate sobre as profissões do campo da Comunicação interessa especialmente às instituições que representam essas profissões e àquelas que formam os profissionais para exercê-las. É possível dizer que para as organizações privadas, instituições públicas e entidades sociais que dependem de visibilidade, comunicação e relacionamentos estratégicos interessará, sobremaneira, a competência dos profissionais e a produção de uma comunicação capaz de produzir visibilidade, credibilidade em torno de uma imagem pública favorável à obtenção de vendas, apoio, votos etc. Para tanto concorrem os profissionais e especialistas de relações públicas, propaganda, jornalismo, produtores audiovisuais, web e marketing, além de outros capazes de pensar e criar formas, textos e espaços estratégicos.

Nesse sentido é preciso entender o pragmatismo das organizações em relação à sua comunicação que desequilibra a dimensão conceitual sobre limites e convergências dos diferentes modos de se comunicar, ou seja, é preciso obter resultados da associação da Comunicação Institucional (Assessoria de Imprensa, Relações Públicas) com a Comunicação Mercadológica (Marketing e Publicidade). A execução desses processos é realizada estrategicamente pelos profissionais de comunicação com competências (assessoria, planejamento, pesquisa, texto, imagem etc.), formação (relações-públicas, jornalistas, publicitários, profissionais de marketing) e domínios específicos (gráfico, digital, eletrônico, web etc.).

Nas organizações privadas, todas as ações comunicacionais estão direcionadas à venda de seus produtos e serviços, à ocupação de mercado e à conquista de um consumidor fiel e insatisfeito. Interessa a essas organizações se posicionarem no mercado e auferirem uma imagem que gere novos investimentos. Em 
meio a isso, elas poderão expor seus investimentos institucionais para ratificar sua responsabilidade social, por exemplo.

Para as organizações públicas (governos, Legislativo, Judiciário, fundações) interessa prestar serviços, angariar opiniões favoráveis e ter uma imagem pública que gere opiniões favoráveis, posicionamentos e votos. Sua atuação é mensurável pelos índices das sondagens de opinião pública e pela manifestação da sociedade. $\mathrm{O}$ mesmo processo de busca de visibilidade e credibilidade das empresas se repete, acrescido da responsabilidade da representação, do poder atribuído pela sociedade, pelo eleitor.

Ao demarcar a dimensão pragmática, pretendo ressaltar objetivos, estratégias, profissionais e produtos das organizações que se impõem e podem tornar anacrônico o debate, por exemplo, sobre os limites de Relações Públicas e Comunicação Organizacional e, assim, se transformar em uma armadilha tautológica. Diante disso, a dimensão conceitual se impõe quando é proposto o debate sobre possíveis diferenças e singularidades entre Comunicação Organizacional e Relações Públicas. Por quê? Para quê?

Defendo que as duas modalidades de comunicação (institucional e mercadológica) podem ocorrer plenamente nas organizações privadas, sendo que nas instituições públicas e sociais predomina a Comunicação Institucional. Outro aspecto refere-se à abrangência desses conceitos, considerando as áreas de atuação, os profissionais e as estratégias em jogo. Todo tipo de comunicação engendrada pelas organizações empresariais e pelas instituições políticas, por exemplo, terá a dimensão persuasiva identificável em todos os produtos comunicativos e todos os processos de relacionamento. Os eventos, a propaganda, a publicidade, promoções, publicações respondem a uma estratégia comunicacional para promoção de serviços, produtos, ideias, ações e o estabelecimento de relações eficazes na obtenção de venda, apoio e boas opiniões. O Jornalismo, por sua vez, exercido como Assessoria de Imprensa também cumprirá essa função estratégica e pode estabelecer o contraponto da credibilidade em relação à Publicidade. Sua ação chega aos jornalistas das redações nas empresas de comunicação, cuja profissão é exercer a vigilância sobre os poderes. Ocupar espaço na mídia é tão importante quanto o investimento em propaganda. É, ao contrário da propaganda e das relações públicas, um lugar incontrolável e, por princípio, de total autonomia. Com essa síntese, pode-se inferir que a Comunicação Organizacional seria o conceito guarda-chuva dos modos de comunicação de qualquer tipo de organização, a soma de todas as comunicações.

Os resultados da produção de informações e de processos comunicativos e a costura de todos os fragmentos expostos pela organização incidirão na formação de uma imagem pública. Para que ocorra essa síntese é necessário que haja centralidade e coerência, ou seja, um projeto estratégico e integrado de visibilidade, para o qual as Relações Públicas reúnem todos os requisitos, como a profissão, a habilitação capaz de dar unidade e avaliar. 
O debate sobre Comunicação Organizacional e Relações Públicas é importante, pois possibilita refletir sobre o poder da comunicação das organizações e as modalidades de comunicação vinculadas a ações e produtos criados e administrados por profissionais de comunicação, especialmente relações-públicas, jornalistas e publicitários. Mas é a área de Relações Públicas que possui na sua natureza a essência da totalidade da Comunicação, o que torna o profissional mais habilitado para planejar e administrar estrategicamente as diferentes modalidades de Comunicação. A execução dependerá das outras competências do campo da Comunicação.

As modalidades de comunicação pública, política e organizacional são de caráter institucional e possuem vários níveis de dependência e complexidade. Por exemplo, a Comunicação Pública e a Comunicação Política dependem da informação gerada pelo sistema de comunicação midiática que permite visibilidade e sugere credibilidade. No que tange à Comunicação Organizacional, a complexidade está na combinação permanente entre a sua dimensão institucional marcada pela difusão de suas funções sociais, relações com públicos, investimentos públicos e, simultaneamente, a agressividade na conquista de mercados e consumidores. A imagem conquistada pela organização será a soma desses procedimentos.

De qualquer modo os discursos de todas as comunicações podem ser confundidos, somados, hibridizados. Para o eleitor, leitor, consumidor, espectador, individualmente ou em grupo, importará a informação adequada às suas necessidades e expectativas. A nós, pesquisadores e profissionais, interessa a manutenção do debate sobre a centralidade e as estratégias de comunicação dos diferentes sistemas e a qualidade das ações e dos produtos gerados nesses espaços institucionais, mercadológicos e midiáticos, espaços de poder que abrigam a tradução, as conversões e as adaptações de verdades e realidades, ininterruptamente.

\section{Referências}

SIMÕES, R. Porto. Relações públicas: função política. São Paulo: Summus, 1995.

Weber, Maria Helena Comunicação: estratégia vital para a saúde. In: PITTA, Áurea M. da Rocha Saúde \& comunicação: visibilidades e silêncios. São Paulo: Hucitec / Abrasco, 1995. p.151-165.

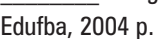

. Imagem pública. In: RUBIM, Antonio A. Canelas (Org.). Comunicação e política: conceitos e abordagens. Salvador: . Na comunicação pública, a captura do voto. Logos - Comunicação e Universidade, UERJ, a. 14, n. 27, 2. sem. 2007. Visibilidade e credibilidade: tensões da comunicação política. In: MAIA, Rousiley; CASTRO, Maria Ceres S. (Org.). Mídia, esfera pública e identidades coletivas. Belo Horizonte: Ed. UFMG, 2003. p. 117-137. 